\title{
Subcutaneous adipocytes from obese hyperinsulinemic women with polycystic ovary syndrome exhibit normal insulin sensitivity but reduced maximal insulin responsiveness
}

\author{
Erika Lystedt* ${ }^{1}$, Hanna Westergren $*^{1}$, Jan Brynhildsen ${ }^{2}$, Lotta Lindh- ${ }^{2}$ strand ${ }^{2}$, Johanna Gustavsson ${ }^{1}$, \\ Fredrik H Nystrom ${ }^{1,3}$, Mats Hammar ${ }^{2}$ and Peter Strålfors ${ }^{1}$ \\ ${ }^{1}$ Department of Cell Biology and Diabetes Research Centre, ${ }^{2}$ Department of Molecular and Clinical Medicine and ${ }^{3}$ Department of Medicine and Care, \\ University of Linköping, SE58185 Linköping, Sweden
}

(Correspondence should be addressed to P Strålfors; Email: peter.stralfors@ibk.liu.se)

${ }^{*}$ E Lystedt and H Westergren contributed equally to this work

\begin{abstract}
Background: Polycystic ovary syndrome (PCOS) has a high prevalence in women and is often associated with insulin resistance and hence with aspects of the so-called metabolic syndrome.

Methods: Ten women diagnosed with PCOS were consecutively included (aged 21-39 years, average $30.2 \pm 1.9$ years; body mass index $28.4-42.5 \mathrm{~kg} / \mathrm{m}^{2}$, average $37.5 \pm 1.7 \mathrm{~kg} / \mathrm{m}^{2}$ (mean \pm s.e.)). Adipocytes were isolated from the subcutaneous fat and, after overnight incubation to recover from insulin resistance due to the surgical cell isolation procedures, they were analyzed for insulin sensitivity. Results: The patients with PCOS exhibited marked clinical hyperinsulinemia with 3.6-fold higher blood levels of C-peptide than a healthy lean control group $(1.7 \pm 0.2$ and $0.5 \pm 0.02 \mathrm{nmol} / \mathrm{l}$ respectively, $P<0.0001)$. The patients with PCOS also exhibited 2.4-fold higher concentrations of serum triacylglycerol $(2.1 \pm 0.3$ and $0.9 \pm 0.06 \mathrm{mmol} / \mathrm{l}$ respectively, $P<0.0001)$, but only slightly elevated blood pressure (118 $\pm 12 / 76 \pm 6$ and $113 \pm 7 / 72 \pm 6 \mathrm{mmHg}$ respectively, $P=0.055 / 0.046)$. However, insulin sensitivity for stimulation of glucose transport in the isolated adipocytes was indistinguishable from a non-PCOS, non-diabetic control group, while the maximal insulin effect on glucose uptake was significantly lower (2.2 \pm 0.2 - and $3.8 \pm 0.8$-fold respectively, $P=0.02)$.

Conclusions: Subcutaneous adipocytes from patients with PCOS do not display reduced insulin sensitivity. The findings show that the insulin resistance of PCOS is qualitatively different from that of type 2 diabetes.
\end{abstract}

European Journal of Endocrinology 153 831-835

\section{Introduction}

Polycystic ovary syndrome (PCOS) has a very high prevalence in women $(5-10 \%)(1)$ and is often associated with insulin resistance and aspects of the so called metabolic syndrome (reviewed in 2-4). Patients usually seek medical attention for menstrual irregularities, infertility or hirsutism. The diagnosis of PCOS is based on two of the following criteria: oligo- or anovulation, clinical and/or biochemical signs of hyperandrogenism, polycystic ovaries and exclusion of other etiologies (5). Women with PCOS display basal and glucose-stimulated hyperinsulinemia (6). Between 16 and $80 \%$ of women with PCOS are obese. Obese women with PCOS are more insulin resistant than weightmatched control subjects or lean women with PCOS $(7,8)$. Indeed, the presence of polycystic ovaries has a stronger connection than obesity to insulin resistance (9). Studies controlling for insulin resistance have found that low high-density lipoprotein (HDL) and high triacylglycerol levels are associated with insulin resistance rather than with PCOS (10). Hypertension, furthermore, is uncommon in women with $\operatorname{PCOS}(11,12)$.

In contrast to whole-body measurements, few reports concern examination of the mechanisms of insulin resistance in PCOS at the cellular level. The maximal insulin-stimulated increase in glucose transport of isolated adipocytes was decreased (13) or unaffected (14) and the sensitivity to insulin stimulation of adipocyte glucose transport was reported to be decreased in two studies of PCOS $(14,15)$. The anti-lipolytic effect of insulin was, however, not affected in adipocytes from women with PCOS, while the catecholamine responsiveness of lipolysis was enhanced (16).

We have recently demonstrated that, when analyzed directly after surgery, isolated adipocytes display an insulin resistance of glucose uptake that is manifest at 
the level of insulin activation of protein kinase B (17). Incubation of the adipocytes overnight reverses this surgery/trauma-induced insulin resistance and allowed us to examine insulin resistance in type 2 diabetes without the interference from the surgery. Examination of adipocytes from patients with type 2 diabetes after overnight incubation thus reveals an insulin resistance to stimulation of glucose transport that is manifest at the level of insulin receptor phosphorylation/activation of the insulin receptor substrate 1 (17). Here, we have used this novel approach to examine insulin sensitivity for glucose uptake in adipocytes from obese patients diagnosed with PCOS, without interference from the surgical/trauma-induced insulin resistance. We report that whereas obese patients with PCOS exhibited strongly elevated levels of circulating C-peptide and fasting serum concentrations of triacylglycerol, their adipocytes exhibited normal insulin sensitivity but reduced maximal responsiveness to insulin.

\section{Materials and methods}

\section{Subjects}

Patients attending the department of obstetrics and gynecology at the University Hospital of Linköping for menstrual irregularities and/or hirsutism were consecutively recruited to the study if they displayed a testosterone/sex hormone binding globulin (SHBG) ratio of $>0.05$ and had at least 36 days of menstrual interval over the last three cycles. In nine of the ten patients ultrasonographic examination of the ovaries was performed and revealed typical signs of polycystic ovaries. Ten women were included (aged 21-39 years, average $30.2 \pm 1.9$ years; body mass index (BMI) 28.4$42.5 \mathrm{~kg} / \mathrm{m}^{2}$, average $37.5 \pm 1.7 \mathrm{~kg} / \mathrm{m}^{2}$ (mean \pm s.E.)). None had known diabetes or used any medication known to interfere with glucose metabolism. Samples of subcutaneous abdominal fat were obtained by incision under local anesthesia. The study was approved by the Local Ethics Committee and participants gave their informed consent.

As a comparison, two groups of subjects without PCOS (non-diabetic women and type 2 diabetic women respectively) were examined earlier (17): pieces of subcutaneous adipose tissue were excised, during elective abdominal surgery and general anesthesia, at the beginning of the operation from eight female non-diabetic control subjects (aged 32-89 years; BMI $17-27 \mathrm{~kg} / \mathrm{m}^{2}$, average $23.4 \pm 1.5 \mathrm{~kg} / \mathrm{m}^{2}$ ) and five female patients with type 2 diabetes (aged 44-72 years; BMI $28-48 \mathrm{~kg} / \mathrm{m}^{2}$, average $38.4 \pm 4.0 \mathrm{~kg} / \mathrm{m}^{2}$; HbA1c 5.7-9.7\%). The patients with diabetes were treated with sulfonylurea, sulfonylurea in combination with metformin, or with insulin. As a control group for clinical parameters, we used 46 women between 20 and 40 years of age randomly obtained from the population of the city of Linköping, Sweden. The subjects were invited by mail to participate in this population study and participation rate was $67 \%$. All these subjects underwent drawing of blood samples and recording of anthropometric parameters in the fasting state at $08.00 \mathrm{~h}$. The detailed description of this population has been published (18).

\section{Isolation and incubation of adipocytes}

Adipocytes were isolated by collagenase (type 1, Worthington, Lakewood, NJ, USA) digestion as described (19). At a final concentration of $100 \mu \mathrm{l}$ packed cell volume per $\mathrm{ml}$, cells were incubated in Krebs-Ringer solution $(60 \mathrm{mmol} / \mathrm{l} \mathrm{NaCl}, 2.3 \mathrm{mmol} / \mathrm{l} \mathrm{KCl}, 1.2 \mathrm{mmol} / \mathrm{l}$ $\left.\mathrm{CaCl}_{2}, 0.6 \mathrm{mmol} / \mathrm{l} \mathrm{MgSO}_{4}, 0.6 \mathrm{mmol} / \mathrm{KH}_{2} \mathrm{PO}_{4}\right)$ and DMEM cell medium at half concentration, containing $20 \mathrm{mmol} / \mathrm{l}$ Hepes, $\mathrm{pH} 7.40,7 \%(\mathrm{w} / \mathrm{v})$ fatty acid-free bovine serum albumin, $100 \mathrm{nmol} / \mathrm{l}$ phenylisopropyladenosine, $0.5 \mathrm{U} / \mathrm{ml}$ adenosine deaminase, $2 \mathrm{mmol} / \mathrm{l}$ glucose, $50 \mathrm{UI} / \mathrm{ml}$ penicillin and $50 \mu \mathrm{g} / \mathrm{ml}$ streptomycin at $37^{\circ} \mathrm{C}$ for $20-24 \mathrm{~h}$ on a shaking water-bath (17). Before analysis, cells were washed and transferred to Krebs-Ringer solution. Insulin was from Sigma-Aldrich (St Louis, MO, USA).

\section{Determination of glucose transport}

Glucose transport was determined as uptake of 2-deoxy-D-[1- $\left.{ }^{3} \mathrm{H}\right]$ glucose (17) after transfer of cells to medium without glucose. 2-Deoxy-D-[1- $\left.{ }^{3} \mathrm{H}\right]$ glucose (Amersham Biotech, Uppsala, Sweden) was added to a final concentration of $50 \mu \mathrm{mol} / \mathrm{l}(10 \mu \mathrm{Ci} / \mathrm{ml})$ and the cells were incubated for $30 \mathrm{~min}$. It was verified that uptake was linear for at least $30 \mathrm{~min}$.

\section{Statistics}

Dose-response curves were compared using the F test with the sigmoidal curve-fitting algorithm in GraphPad Prism 4 (GraphPad Software, Inc., San Diego, CA, USA). The difference between groups was analyzed by Student's $t$-test. The null hypothesis was rejected if $P<0.05$.

\section{Results}

Characteristics of the patients with PCOS are shown in Tables 1 and 2. As a comparison, we have included data from a non-PCOS control group that was matched for age and gender. The PCOS patients were obese as judged by BMI $\left(37.5 \pm 1.7 \mathrm{~kg} / \mathrm{m}^{2}\right.$ (mean \pm S.E.)). The fasting blood glucose was normal, but the patients with PCOS displayed considerably increased levels of fasting C-peptide (3.6-fold higher concentration compared with the non-PCOS controls) (Table 1). The fasting levels of triacylglycerol were also considerably increased in the patients (2.4-fold higher 
Table 1 Clinical characteristics of the study (PCOS) and control groups.

\begin{tabular}{|c|c|c|c|c|}
\hline \multirow[b]{2}{*}{ Parameter } & \multicolumn{2}{|c|}{$\operatorname{PCOS}(n=10)$} & \multirow{2}{*}{$\begin{array}{c}\text { Controls }(n=46) \\
\text { (average } \pm \text { S.E.) }\end{array}$} & \multirow[b]{2}{*}{$\boldsymbol{P}$ value (Student's $t$-test) } \\
\hline & Average \pm S.E. & Range & & \\
\hline Age & 30.2 & $23-39$ & 30.1 & 0.97 \\
\hline BMI $\left(\mathrm{kg} / \mathrm{m}^{2}\right)$ & $37.5 \pm 1.7$ & $28.4-42.2$ & $23.2 \pm 0.5$ & $<0.0001$ \\
\hline Blood pressure $(\mathrm{mmHg})$ & $118 \pm 12 / 76 \pm 6$ & $105-140 / 70-85$ & $113 \pm 7 / 72 \pm 6$ & $0.055 / 0.046$ \\
\hline Fasting glucose $(\mathrm{mmol} / \mathrm{l})$ & $5.0 \pm 0.2$ & $3.9-7.4$ & $4.7 \pm 0.1$ & 0.11 \\
\hline C-peptide (mmol/l) & $1.7 \pm 0.2$ & $0.88-2.87$ & $0.5 \pm 0.02$ & $<0.0001$ \\
\hline Triacylglycerol $(\mathrm{mmol} / \mathrm{l})$ & $2.1 \pm 0.3$ & $1.2-4.6$ & $0.9 \pm 0.6$ & $<0.0001$ \\
\hline Total cholesterol $(\mathrm{mmol} / \mathrm{l})$ & $5.4 \pm 0.3$ & $4.2-7.1$ & $4.5 \pm 0.1$ & 0.0018 \\
\hline LDL-cholesterol & $3.2 \pm 0.2$ & $2.4-4.7$ & $2.8 \pm 0.1$ & 0.088 \\
\hline HDL-cholesterol & $1.2 \pm 0.05$ & $0.9-1.5$ & $1.3 \pm 0.05$ & 0.30 \\
\hline
\end{tabular}

LDL, low density lipoprotein; HDL, high density lipoprotein.

Table 2 Serum concentrations in the PCOS study group $(n=10)$ and normal reference values.

\begin{tabular}{lccc}
\hline & \multicolumn{2}{c}{ Concentration } & \\
\cline { 2 - 3 } Hormone & Average \pm S.E. & Range & Normal reference concentration range \\
\hline Insulin (pmol/l) & $216 \pm 59$ & $76-696$ & $14-160$ \\
Glucose 2 h after glucose load (mmol/l) & $6.8 \pm 0.6$ & $2.5-10.7$ & $<7.9$ \\
Estradiol (pmol/l) & $161 \pm 28$ & $75-360$ & $130-146$ \\
Progesterone (nmol/l) & $1.4 \pm 0.1$ & $<1-13$ & $<3$ \\
LH (U/l) & $8.0 \pm 1.0$ & $2.0-12$ & $<10$ \\
FSH (U/l) & $5.2 \pm 0.4$ & $2.6-6.5$ & $2-10$ \\
Testosterone (nmol/l) & $2.2 \pm 0.1$ & $1.6-2.8$ & $<3.0$ \\
SHBG (nmol/l) & $20.3 \pm 2.5$ & $9.7-37$ & $30-90$ \\
Testosterone/SHBG ratio & $0.14 \pm 0.02$ & $0.08-0.29$ & $<0.06$
\end{tabular}

For simplicity, reference ranges for estradiol, progesterone, luteinizing hormone (LH) and follicle-stimulating hormone (FSH) are given as follicular phase values as none of the patients had signs of ovulation according to menstrual history. Oral glucose tolerance was tested after an over-night fast and measurement of fasting glucose, ingestion of $75 \mathrm{~g}$ glucose and re-analysis of capillary blood glucose after $2 \mathrm{~h}$.

SHBG, sex hormone binding globulin.

concentration). However, only $20 \%$ of the patients with PCOS responded to the oral glucose tolerance test with glucose levels above the diagnostic level for impaired glucose tolerance and all responded with glucose levels below the diagnostic level for diabetes (not shown and Table 1). The metabolic differences between controls and patients could be caused by obesity or factors more specifically related to the polycystic ovary syndrome. We therefore next isolated fat cells from patients with PCOS and from a group of patients with type 2 diabetes matched for BMI as well as from a non-diabetic, non-obese control group.

Adipocytes were isolated from the abdominal subcutaneous adipose tissue of the patients with PCOS and the rates of glucose transport in response to varying concentrations of insulin were examined. Insulin enhanced glucose transport by the adipocytes with half-maximal effect $\left(\mathrm{EC}_{50}\right)$ at $0.03 \mathrm{nmol} / \mathrm{l}$ insulin (Fig. 1). The $\mathrm{EC}_{50}$ and the entire dose-response curve were similar to those obtained from a group of non-diabetic women without PCOS $\left(\mathrm{EC}_{50}=0.03, \mathrm{BMI}=23.4 \pm 1.5 \mathrm{~kg} / \mathrm{m}^{2}\right)$ (17) and therefore were also markedly more sensitive to insulin stimulation than cells from a group of type 2 diabetic women $\left(\mathrm{EC}_{50}=0.15\right)$ with an average BMI of $38.4 \pm 4.0 \mathrm{~kg} / \mathrm{m}^{2}$ (17) (Fig. 1). This demonstrates that

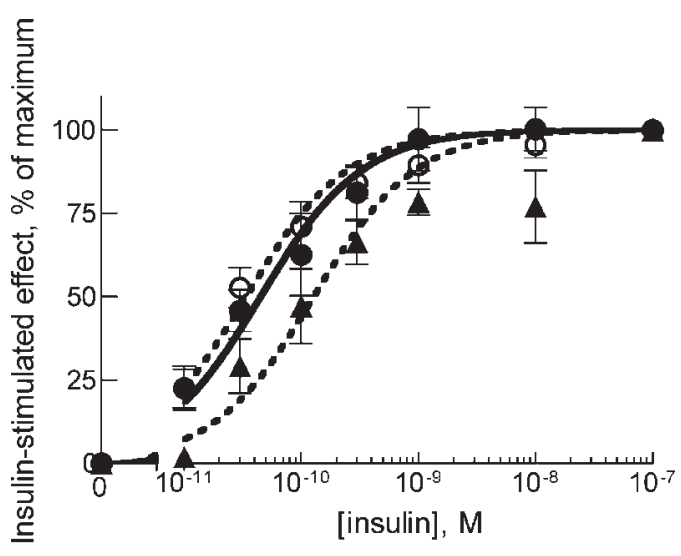

Figure 1 Dose-response curves for stimulation of glucose transport by insulin. Adipocytes from patients with PCOS were incubated with insulin at the indicated concentrations for $10 \mathrm{~min}$. Glucose transport was determined as uptake of 2-deoxy-D$\left[1-{ }^{3} \mathrm{H}\right]$ glucose by the cells (solid circles, continuous line, mean \pm S.E., $n=10$ ). Also plotted are the dose-response curve for a normal control group of women (open circles, dashed line, mean \pm S.E., $n=8$ ) and for a group of type 2 diabetic women (triangles, dashed line, mean \pm S.E., $n=5$ ) values taken from (17). The dose-response curve for the PCOS patients was significantly different from that of the type 2 diabetic women, $P<0.05$, but not from the normal control group. 
subcutaneous adipocytes in this obese group of patients with PCOS had normal insulin sensitivity for stimulation of glucose uptake.

The basal and maximal insulin-stimulated glucose uptake varied widely between individuals, ranging from 18 to $98 \mathrm{nmol} / \mathrm{min} / \mathrm{l}$ of cells $(110 \pm 15, n=10)$ and from 44 to $173 \mathrm{nmol} / \mathrm{min} / \mathrm{l}$ of cells $(140 \pm 33$, $n=10)$ respectively, and were not significantly different from those of non-diabetic women without PCOS (17). The maximal insulin effect was, however, lower $(P=0.02)$ in adipocytes from the group of patients with PCOS $(2.2 \pm 0.2$-fold stimulation, $n=10)$ compared with non-diabetic women without PCOS (3.8 \pm 0.8 -fold stimulation, $n=8$ ) (17).

\section{Discussion}

The patients in our study were markedly obese compared with a non-PCOS control population. They also exhibited a marked hyperinsulinemia with, on average, 3.6-fold higher levels of fasting C-peptide than lean controls. Since fasting blood glucose concentrations were similar in the patients and in the control group this degree of C-peptide elevation is a clear indicator of resistance to the metabolic effects of insulin in combination with sufficient function of the pancreatic beta-cells. Such high production of insulin could have clinical implications for patients with PCOS since insulin has been shown to lower the levels of SHBG (20). Low levels of SHBG serve to increase the concentration of free testosterone resulting in hirsutism and acne.

Despite clear signs of a reduction of the sensitivity to insulin in vivo we could not detect any differences in the insulin sensitivity to glucose uptake in adipocytes isolated from the patients with PCOS. We have previously reported that when fat cells are studied immediately after surgery, the insulin resistance following the surgical procedure and isolation of the cells masks differences in signaling that can be observed only when the adipocytes are allowed to recover by incubation overnight (17). Using this approach to examine the fat cells, we found no difference in the sensitivity to insulin in subcutaneous adipocytes from patients with PCOS as compared with non-PCOS women. The maximal insulin responsiveness was, however, reduced in the patients with PCOS compared with the control group. This is in contrast to findings in patients with type 2 diabetes whose adipocytes exhibit reduced insulin sensitivity, but normal insulin responsiveness (17). It is, of course, a distinct possibility that the visceral, but not subcutaneous, adipose tissue is insulin resistant in PCOS, in contrast to the situation in type 2 diabetes (17).

Ciaraldi et al. have studied the effects of insulin on insulin-induced glucose uptake in adipocytes from PCOS patients directly after cell isolation and found this to be clearly perturbed (14). Taken together, the results of our study and that by Ciaraldi et al. indicate a reversible insulin resistance in adipocytes from patients with PCOS, similar to the situation in cells directly after the surgical cell isolation procedure (17). This reversibility points to humoral rather than structural factors underlying the insulin resistance of the fat cells in PCOS, and is different from what we have previously shown to be the case in adipocytes from patients with overt type 2 diabetes, which is not reversible (17). It is possible that the rapidly reversible insulin resistance of isolated adipocytes is specific for patients with PCOS. It might, however, also represent a pre-diabetic state. The fact that the patients with PCOS did not exhibit lowered levels of circulating HDL (Table 1) is compatible with this. It should be noted, however, that the average BMI of these patients with PCOS was the same as in a group of women with type 2 diabetes, whose adipocytes were markedly insulin resistant in the same assay as used herein (17). In this context it is interesting that the indices commonly utilized to determine insulin resistance in diabetes, the quantitative insulin sensitivity check index (QUICKI) and the homeostasis model of assessment (HOMA), do not correlate with the euglycemic clamp determination of insulin sensitivity in women with PCOS in contrast to diabetes (21).

In conclusion, a group of very obese women with PCOS had a marked hyperinsulinemia as evidenced by high levels of circulating C-peptide, while their abdominal subcutaneous adipocytes displayed normal sensitivity for insulin stimulation of glucose transport, but reduced maximal responsiveness.

\section{Acknowledgements}

We thank Preben Kjolhede and Gheorghe Andreescu for supplying adipose tissue. This work was financially supported by research grants from Östergötland County Council, Linköping University Hospital Research Funds, the Swedish Diabetes Association, and the Swedish Research Council.

\section{References}

1 Diamanti-Kandarakis E, Kouli CR, Bergiele AT, Filandra FA, Tsianateli TC, Spina GG, Zapanti ED \& Bartzis MI. A survey of the polycystic ovary syndrome in the Greek island of Lesbos: hormonal and metabolic profile. Journal of Clinical Endocrinology and Metabolism 199984 4006-4011.

2 Sharpless JL. Polycystic ovary syndrome and the metabolic syndrome. Clinical Diabetes 200321 154-161.

3 Dunaif A. Insulin resistance and the polycystic ovary syndrome: mechanisms and implications for pathogenesis. Endocrine Reviews $199718774-800$.

4 Ciampelli M \& Lanzone A. Insulin and polycystic ovary syndrome: a new look at an old subject. Gynecological Endocrinology 199812 277-292.

5 Revised 2003 concensus on diagnostic criteria and long-term health risks related to polycystic ovary syndrome. Fertility and Sterility 200481 19-25. 
6 Burghen GA, Givens JR \& Kitabchi AE. Correlation of hyperandrogenism with hyperinsulinism in polycystic ovarian disease. Journal of Clinical Endocrinology and Metabolism 198050 113-116.

7 Dunaif A, Segal KR, Futterweit W \& Dobrjansky A. Profound peripheral insulin resitance, independent of obesity, in polycystic ovary syndrome. Diabetes 198938 1165-1174.

8 Rajkhowa M, Bicknell J, Jones M \& Clayton RN. Insulin sensitivity in women with polycystic ovary syndrome: relationship to hyperandrogenemia. Fertility and Sterility 1994 61 605-612.

9 Cresswell J, Fraser RB, Bruce C, Egger P, Phillips D \& Parker DJP. Relationship between polycystic ovaries, body mass index and insulin resistance. Acta Obstetrica et Gynecologica Scandinavica $20038261-64$.

10 Robinson S, Henderson AD, Gelding SV, Kiddy D, Niththyananthan R, Bush A, Richmond W, Johnston DG \& Franks S. Dyslipidaemia is associated with insulin resistance in women with polycystic ovaries. Clinical Endocrinology $1996 \mathbf{4 4}$ 277-284.

11 Sampson M, Kong C, Patel A, Unwin R \& Jacobs HS. Ambulatory blood pressure profiles and plasminogen activator inhibitor (PAI1) activity in lean women with and without the polycystic ovary syndrome. Clinical Endocrinology 199645 623-629.

12 Zimmermann S, Phillips RA, Dunaif A, Finegood DT, Wilkenfeld C, Ardeljan M, Gorlin R \& Krakoff LR. Polycystic ovary syndrome: lack of hypertension despite profound insulin resistance. Journal of Clinical Endocrinology and Metabolism 199275 508-513.

13 Rosenbaum D, Haber RS \& Dunaif A. Insulin resistance in polycystic ovary syndrome: decreased expression of GLUT-4 glucose transporters in adipocytes. American Journal of Physiology 1993 264 E197-E202.

14 Ciaraldi TP, el-Roeiy A, Madar Z, Reichart D, Olefsky JM \& Yen SS. Cellular mechanisms of insulin resistance in polycystic ovarian syndrome. Journal of Clinical Endocrinology and Metabolism 1992 75 577-583.

15 Dunaif A, Segal KR, Shelley DR, Green G, Dobrjansky A \& Licholai T. Evidence for distinctive and intrinsic defects in insulin action in polycystic ovary syndrome. Diabetes $1992 \mathbf{4 1}$ $1257-1266$.

16 Ek I, Arner P, Ryden M, Holm C, Thörne A, Hoffstedt J \& Wahrenberg H. A unique defect in the regulation of visceral fat cell lipolysis in the polycystic ovary syndrome as an early link to insulin resistance. Diabetes $2002 \mathbf{5 1} 484-492$.

17 Danielsson A, Öst A, Lystedt E, Kjolhede P, Gustavsson J, Nystrom FH \& Strålfors P. Insulin resistance in human adipocytes downstream of IRS1 after surgical cell isolation, but at the level of phosphorylation of IRS1 in type 2 diabetes. FEBS Journal 2005 $272141-151$.

18 Nystrom FH, Ohman PK, Ekman BA, Osterlund MK, Karlberg BE \& Arnqvist HJ. Population-based reference values for IGF-I and IGF-binding protein-1: relations with metabolic and anthropometric variables. European Journal of Endocrinology 1997136 165-172.

19 Strålfors P \& Honnor RC. Insulin-induced dephosphorylation of hormone-sensitive lipase. Correlation with lipolysis and cAMPdependent protein kinase activity. European Journal of Biochemistry 1989182 379-385.

20 Nestler JE, Powers LP, Matt DW, Steingold KA, Plymate SR, Rittmaster RS, Clore JN \& Blackard WG. A direct effect of hyperinsulinemia on serum sex-hormone binding globulin levels in obese women with the polycystic ovary syndrome. Journal of Clinical Endocrinology and Metabolism 199172 83-89.

21 Diamanti-Kandarakis E, Kouli C, Alexandraki K \& Spina G. Failure of mathematical indices to accurately assess insulin resistance in lean, overweight, or obese women with polycystic ovarry syndrome. Journal of Clinical Endocrinology and Metabolism 200489 $1273-1276$.

Received 11 May 2005

Accepted 1 September 2005 